\title{
T. IIPLICAÇÕES DAS REDES SOCIAIS ONLINE PARA A EDUCAÇÃO DA SENSIBILIDADE
}

\author{
IMPLICATIONS OF ONLINE SOCIAL MEDIA TO SENSITIVITY EDUCATION
}

\author{
Nathália Gonçalves Campos ${ }^{1}$ \\ Carolina Laurenti ${ }^{2}$
}

\section{Resumo}

A violência pode ser identificada na sociedade contemporânea tanto no ambiente virtual quanto no não virtual. Os comportamentos violentos no ambiente não virtual foram analisados por Abib como sendo frutos do conflito entre as sensibilidades primeva e evoluída e propõe, então, 0 projeto de educação da sensibilidade, que visa restaurar o equilíbrio entre essas sensibilidades. Este trabalho buscou avaliar se as redes sociais online podem contribuir para a educação da sensibilidade cumprindo com seus princípios e estratégias. Para isso, foi realizada uma pesquisa teórico-bibliográfica, cujas fontes foram 34 artigos publicados na revista Computers and Human Behavior; e a análise se pautou nos conceitos fundamentais da educação da sensibilidade. Foram identificados comportamentos favoráveis (pró-sociais) os quais se pautam nos princípios e estratégias da educação da sensibilidade, e comportamentos desfavoráveis (antissociais) que não são condizentes com os princípios e estratégias da educação da sensibilidade. Concluiu-se que as redes sociais online poderiam viabilizar a educação da sensibilidade, mas as possibilidades de anonimato, perfis falsos, e a própria estrutura da Internet pode dificultar o seu desenvolvimento.

Palavras-chave: Educação da sensibilidade; redes sociais online; análise do comportamento.

\section{Abstract}

Violence can be identified in contemporary society in both virtual and non-virtual environments. Violent behaviors in the non-virtual environment were analyzed by Abib as being the result of the conflict between primeval and evolved sensibilities and propose, therefore, the project of sensitivity education, which aims to restore the balance between these sensitivities. This paper aimed to evaluate if online social media can contribute to the sensitivity education, complying with its principles and strategies. For this, theoretical-bibliographical research was conducted, whose sources were 34 articles published in the journal Computers and Human Behavior; and the analysis was based on the fundamental concepts of sensitivity education. Favorable (prosocial) behaviors which are based on the principles and strategies of sensitivity education were identified, and unfavorable (antisocial) behaviors that are not consistent with the principles and strategies of sensitivity education. It was concluded that online social networks could enable the education of sensitivity, but the possibilities of anonymity, false profiles, and the very structure of the Internet can hinder its development.

Keywords: Sensitivity education; online social media; behavior analysis.

1 Universidade Estadual de Maringá-Brasil, graduanda de Psicologia, nathaliagccampos@gmail.com.
https://orcid.org/0000-0002-7710-0566
2 Universidade Estadual de Maringá-Brasil, doutora em Filosofia pela Universidade Federal de São Carlos e professora adjunta no
Departamento de Psicologia na Universidade Estadual de Maringá, laurenticarol@gmail.com. https://orcid.org/0000-0002-5247-9610 


\section{INTRODUÇÃO}

Os casos de violência que podem ser identificados cotidianamente acontecem tanto no ambiente virtual quanto no não-virtual. Por exemplo, ao fazer uma busca assistemática em sites de notícia com a palavra-chave "violência", é apresentada uma variedade de casos envolvendo crimes de homofobia, intolerância religiosa, racismo, sexismo, entre outros. Esses crimes envolvem homicídios, guerras, atentados terroristas, genocídios, e também crimes virtuais como o ciberbullying, entre muitos outros. A Análise do Comportamento tem se debruçado sobre o fenômeno da violência (Abib, 2007; Carvalho Neto, Alves, \& Baptista, 2007; Soares \& Carvalho Neto, 2016). De acordo com Laurenti e Lopes (2015), esses atos de maldade podem acontecer em qualquer tipo de sociedade, não excluindo a moderna e civilizada, mas que isso não é elucidado pela noção de uma essência humana boa ou má. Assim, as possibilidades de "bondade" e "maldade" podem ser ampliadas pelas práticas culturais, pois uma cultura não apenas reproduz suas práticas, mas também geram novas (Abib, 2007)

Abib (2007) compreende os conflitos humanos no contexto não-virtual em termos de um desequilíbrio entre as sensibilidades primeva e evoluída. A sensibilidade primeva estaria relacionada a comportamentos que possuem valor de sobrevivência para a espécie, enquanto que a sensibilidade evoluída seria a capacidade dos indivíduos serem afetados pelas consequências reforçadoras de seu comportamento. Tais consequências, além de aumentarem a frequência do tipo de comportamento que as produzem, também geram prazer. No contexto evolutivo, ambas as sensibilidades trabalharam em conjunto promovendo a sobrevivência e também gerando prazer. Entretanto, 0 autor explica que, no caso do ser humano, com o advento da cultura e das práticas culturais, em particular as ocidentais capitalistas, essas sensibilidades (primeva e evoluída) passaram a competir entre si. Práticas culturais como violência, consumismo, competição, exploração do meio ambiente podem gerar prazer imediato e consequências aversivas tardias, ameaçando a sobrevivência das espécies, humana e não humana.

Com as redes sociais online, diferentes formas de relações sociais foram estabelecidas e se expandiram, tornando ainda mais complexas essas interações (Wang, Pereira \& Andery, 2016). Nesse âmbito, os reforçadores positivos podem ser "reproduzidos globalmente, infinitamente, instantaneamente, com a mesma qualidade" (Wang, Pereira \& Andery, 2016, p. 161). Em contrapartida, as eventuais consequências aversivas que podem advir de comportamentos violentos emitidos no contexto das redes sociais online podem ser dissipadas pela possibilidade de anonimato que é conferida pela Internet (Laurenti \& Lopes, 2015).

Deste modo os comportamentos "maldosos" (i.e., que produzem prejuízo ou dano a outro) emitidos no contexto das redes sociais online ganham espaço, então, por conta de "contingências que diminuem ou bloqueiam a sensibilidade do comportamento ao mundo, sobretudo, quando outras pessoas participam desse mundo" (Laurenti \& Lopes, 2015, p. 34). Ou seja, a mediação tecnológica funciona como uma "barreira" entre o comportamento e as consequências por ele produzidas. Ao publicar ou compartilhar um conteúdo de natureza preconceituosa, por exemplo, o indivíduo dispõe de alguns mecanismos online (bloquear opiniões diversas, ocultar sua identidade verdadeira, expor a opinião para apenas um determinado grupo, etc) que contribuem para que ele não fique sob controle das consequências aversivas produzidas no comportamento da pessoa afetada por ele. Paralelamente, o indivíduo também dispõe de múltiplas possibilidades de obter reforçadores positivos imediatos, como comportamentos de consumo, facilitados pelas compras online, possibilidades de comunicação com outros usuários, acesso a 
informações e conteúdos digitais variados, jogos online, todos sendo selecionados pelo próprio usuário de acordo com os seus gostos particulares, de modo que não ocorram situações desprazerosas.

Assim, as práticas culturais vigentes na sociedade contemporânea promovem comportamentos que produzem o prazer desmedido e a intolerância aos desprazeres, ou seja, utilizam de reforçadores positivos e negativos imediatos desvinculados do valor de sobrevivência. Diante desse conflito, Abib (2007) propõe um projeto de educação da sensibilidade, o qual possui como objetivo principal a harmonização das sensibilidades primeva e evoluída, bem como o controle do imediatismo da natureza apropriado pelas práticas culturais que ameaçam a sobrevivência, promovendo, então, o fortalecimento de contingências favoráveis para a sobrevivência dos indivíduos e da própria cultura.

Bogo (2017) buscou esclarecer a proposta de educação da sensibilidade discutindo-a em termos de princípios e estratégias. Os "princípios podem ser definidos como regras fundamentais que devem perpassar todas as estratégias com vistas a educar a sensibilidade" (p. 29). São descritos quatro princípios: a utilização do reforço positivo imediato; vinculação do reforço positivo imediato a comportamentos que têm valor de sobrevivência para as culturas; ou, vinculado a comportamentos que não a ameacem; diminuição ou o abandono de práticas punitivas.

De acordo com Abib (2007), as mudanças em práticas culturais a ser promovidas pela educação da sensibilidade precisam considerar que "a produção de consequências culturais não pode se tornar independente do reforço" (p. 64), pois o reforço é necessário para manter e aperfeiçoar os comportamentos que podem dar origem às consequências culturais que possuem valor de sobrevivência. Além disso, existem comportamentos que não possuem valor de sobrevivência, mas que também não a ameaçam. Por fim, a punição somente deve ser utilizada quando for apresentado um comportamento incompatível que seja reforçado positivamente e imediatamente, uma vez que a punição imediata não é o melhor caminho para enfraquecer uma contingência, além de gerar subprodutos nocivos para os indivíduos.

Já as estratégias são descritas por Bogo (2017) como os meios para realizar a educação da sensibilidade, isto é, com as estratégias torna-se possível restaurar o equilíbrio das sensibilidades, porém, apenas se essas forem pautadas nos princípios, pois esses são reguladores e norteadores da proposta da educação da sensibilidade. A autora organizou as estratégias em: educação do sentimento, educação ética, educação para liberdade, formação do autocontrole e do indivíduo criativo.

A educação do sentimento envolve o hedonismo, isto é, as noções de prazer e desprazer. Portanto, a educação do sentimento visa a educação do prazer. Seria, então, a capacidade de identificar os prazeres que devem ser evitados, uma vez que conduzem à infelicidade, e as dores que devem ser toleradas, isto, pois, conduzirão à felicidade. Além disso, para o desenvolvimento dessa educação faz-se necessários disciplinas que possam poduzir prazer por meio de esportes, cantar, ouvir música, dançar pintar, de modo não competitivo ou remunerado (Bogo \& Melo, 2019).

Outra estratégia é a educação ética, a qual possibilita um novo tipo de sensibilidade, a sensibilidade cultural, a qual envolve os comportamentos éticos e o sentimento de dever fazer o bem para o ser humano e para todas as espécies (Abib, 2007). "a finalidade principal é, de um lado, combater a ética do egoísmo e suas formas perversas de individualismo e, de outro, construir uma ética da justiça” (Abib, 2007, p. 72).

A partir da educação ética que se pode pensar em outra estratégia, a educação para a liberdade. A liberdade pode ser entendida como liberdade de e liberdade para. Abib (2007) explica que "liberdade de significa liberdade de punição (de dor e de perda de prazer) e de reforço (de prazer e de alívio de dor) que atenta contra a vida ou que é 
fonte de injustiça" (pp. 71-72). Já a liberdade para significa a "construção de culturas em que o prazer e o alívio de dor não ameacem a vida e em que o outro também tenha direito ao reforço" (Abib, 2007, p. 72).

Outra estratégia proposta é o autocontrole. Skinner (1953/2003) explica que este é o modo com que o indivíduo controla partes de seu próprio comportamento quando ocorrem respostas com consequências conflituosas. Abib (2007) expõe que ao educar as crianças sob valores éticos o autocontrole conduzirá os indivíduos para um hedonismo educado, e consequentemente para uma ética justa. Por fim, outra estratégia da educação da sensibilidade é a formação do indivíduo criativo. Essa estratégia propõe que para formar indivíduos criativos é necessário torná-los sensiveis sobre os outros mundos e culturas. Somente assim é possível construir uma cultura de alteridade, ". . . a cultura que estabelece as condições para 0 afloramento da pluralidade e diversidade, que são necessárias para a compreensão de mundos diferentes" (Abib, 2007, p. 78).

A educação da sensibilidade busca, então, educar o sentimento, promovendo a compreensão de que existem prazeres imediatos que podem conduzir a sofrimento tardio e desprazeres momentâneos que resultam em prazeres duradouros e benéficos para o indivíduo e a sociedade. Tendo em vista que uma das principais práticas culturais vigentes é a utilização das redes sociais online como meio de comunicação e interação, e que essa permite 0 acesso a diferentes pessoas de diferentes culturas, os indivíduos nas redes sociais online estariam mais respeitosos às diferenças? Sendo assim, é possível indagar se os comportamentos promovidos pelas redes sociais online podem ser estratégias para a educação da sensibilidade, e se são pautadas nos princípios norteadores desta educação.

Dada a importância da proposta da educação da sensibilidade surge a necessidade de ampliar o contexto de sua discussão, uma vez que nem Abib (2007) nem Bogo (2017) discutiram a educação da sensibilidade no âmbito das redes sociais online. Assim o objetivo deste artigo é sondar, de um lado, se a forma de interação por essas redes sociais pode contribuir para a educação da sensibilidade e, por outro, se essa proposta é aplicável a essas novas formas de relação social. $O$ trabalho, ao fazer isso, pretende contribuir para a elucidação da proposta da educação da sensibilidade, avaliando suas potencialidades e limites, bem como suas ressonâncias contemporâneas.

\section{PROCEDIMENTOS METODOLÓGICOS}

Foi realizada uma pesquisa de natureza teórico-bibliográfica cujas fontes foram artigos publicados na revista eletrônica Computers in Human Behavior. A escolha desse periódico é justificada por se tratar de uma revista acadêmica dedicada a examinar o uso de computadores, incluindo também o seu impacto nas interações humanas. Por isso, vários estudos são pertinentes a uma discussão psicológica.

O periódico apresenta um elevado fluxo de publicações, sendo um volume por mês, contendo em média 30 artigos publicados por volume. Deste modo, para os critérios de inclusão foi realizado um recorte temporal de 2010 a 2018, visto que a partir de 2014 a revista triplicou o seu número de publicações. Além disso, foram selecionados artigos que contiveram no título, no resumo e/ou no corpo do texto palavras-chave associadas tanto à discussão sobre as relações sociais mediadas pela Internet quanto aquelas relacionadas à proposta de educação da sensibilidade. Foi utilizada a palavra chave "online behavior" combinada com palavras que remetiam aos princípios e estratégias da educação da sensibilidade (health behavior, mental health, culture, benefit, feelings, love, sentimento, sensivity, emotions, otherness, pleasure, enjoyment, cooperation, imagination, art, ethical, justice, self control, empathy, hedonism). Também foram combinadas palavras que se relacionam aos comportamentos que, de algum modo, 
transgridam os princípios e estratégias dessa proposta (maladaptative behavior, prejudice, individualism, injustice, intolerance, punishment).

Já para os critérios de exclusão, foram descartados os artigos que não possuíam como temática de discussão os comportamentos sociais online, ou que apresentavam questões referentes apenas ao funcionamento da Internet sob a perspectiva da programação, como análise de funcionamento de programas, e de softwares, mas que não possuíam relação com a área da psicologia, por exemplo. A sistematização e análise dos artigos selecionados foram realizadas na forma de fichamentos de resumo informativo norteados por 9 questões, que tinham 0 objetivo de identificar os comportamentos discutidos no artigo, se existiam diferenças entre esses comportamentos online e off-line, quais as consequências desses comportamentos e se eram positivas ou negativas, em quais níveis elas se verificavam (individual, social ou cultural), e se esses comportamentos eram compatíveis ou incompatíveis com a educação da sensibilidade. Por fim, a avaliação da compatibilidade das relações sociais online com os princípios e estratégias da educação da sensibilidade foi realizada com base em categorias de análise que permitiram estruturar as informações obtidas na forma de um texto.

\section{RESULTADOS E DISCUSSÃO}

Foram obtidos 34 artigos para análise. Com base na elucidação dos conceitos fundamentais e da própria definição da educação da sensibilidade, foi elaborada uma categorização dos comportamentos identificados nos artigos, os quais serão apresentados em condições favoráveis e desfavoráveis à educação da sensibilidade. Pode-se definir que as condições favoráveis para a educação da sensibilidade são comportamentos que estão pautados nos princípios e nas estratégias dessa proposta educacional, ou que não os ferem. Já as condições desfavoráveis são opostas, ou seja, não estão de acordo com os princípios ou estratégias, ou ferem ambos.

Além disso, Ferenczi, Marshall e Bejanyan (2017) apresentaram duas categorias de comportamentos que podem ser identificados nas redes sociais online: comportamentos antissociais e pró-sociais. Os comportamentos antissociais são desfavoráveis à educação da sensibilidade uma vez que são descritos como egoístas, violentos, que não se baseiam e nem promovem a alteridade e empatia. Em geral, são comportamentos os quais têm suas consequências nas redes sociais online dissipadas e os indivíduos tendem a não considerar o impacto delas nos demais usuários que compartilham esse ambiente. Já os comportamentos pró-sociais são aqueles que visam o relacionamento com outros indivíduos por meio de conversas, comentários, entre outros comportamentos possíveis nas redes sociais online, com a finalidade de se conectar com os outros e desenvolver o sentimento de pertencimento a um determinado grupo ou comunidade. Deste modo, a descrição dos comportamentos identificados nos artigos selecionados pautou-se nessa categorização desenvolvida com base nos conceitos da educação da sensibilidade, bem como nas descrições de Ferenczi et al. (2017), os quais serão apresentados abaixo:

\section{Comportamentos favoráveis à educação da sensibilidade}

Os comportamentos favoráveis à educação da sensibilidade são aqueles que cumprem com os seus princípios e estratégias, ou que não os ferem, isto é, são comportamentos que geram prazer, ou alívio de desprazer que não são prejudiciais para os indivíduos, espécies e culturas. São, então, comportamentos que utilizam do hedonismo educado, 
da ética justa e das demais estratégias propostas pela educação da sensibilidade. Nos artigos selecionados para análise, a Internet foi descrita como um ambiente que proporciona emitir comportamentos variados, como jogar, conversar com outras pessoas por meio das redes sociais online ou em sites de relacionamento, ou então como um meio para a realização de trabalhos variados, estudos, entre outros.

Contena, Loscalzo e Taddei (2015) explicam o comportamento de auto-revelação (self-disclosure). Esse comportamento se baseia em alguns fatores como a reciprocidade, a duração da troca de informações, a intimidade/intensidade das informações trocadas e a confiança. Ainda há a ideia de controle sobre a informação, que está diretamente relacionada com a confiança e a privacidade, ou seja, os indivíduos controlam com quem, quando e como compartilham suas informações. As redes sociais online têm seu funcionamento baseado nessas trocas de informações, que se dão por meio de comportamentos como compartilhar textos, fotos, vídeos, entre outros recursos, que possuem como objetivo expor a opinião sobre um determinado assunto, ou até mesmo sobre si (Bryce \& Fraser, 2014; Contena, Loscalzo \& Taddei, 2015).

Ferenczi et al. (2017) e Kimbrough, Guadagn, Nicole, Muscanell \& Dill (2013) levantam hipóteses sobre a diferença de gênero e o uso das redes sociais, e confirmam que as mulheres utilizam mais as redes sociais online emitindo comportamentos pró-sociais em comparação com os homens. Isso porque a cultura estabelece contingências de comportamentos diferentes entre os gêneros feminino e masculino, isto é, as mulheres são reforçadas a emitir comportamentos de comunicação, afetividade e alteridade, enquanto que os homens são reforçados por emitirem comportamentos competitivos e narcísicos. Ferenczi et al. (2017) entende que o comportamento das mulheres de se revelarem e expressarem socialmente é o que define 0 uso da auto-revelação como um método para aumentar a intimidade relacional com os outros indivíduos, seja online ou off-line.

O comportamento de auto-revelação também é emitido pelos jovens adultos e, principalmente pelos adolescentes. Bryce e Fraser (2014) argumentam que a Internet pode ser identificada como um espaço importante para a exploração da identidade, sexualidade e intimidade. Estabelecimento de vínculos como amizades e interações entre pares são de importância central para a vida dos jovens e representam uma fonte de apoio durante a adolescência. Como resultado, a interação com os amigos emergiu como um dos elementos mais importantes para os jovens participarem do ambiente online (Bryce \& Fraser, 2014). Algumas entidades e organizações utilizam dessas informações compartilhadas pelos usuários para a promoção de eventos, cartilhas de informações entre outros recursos que objetivam, por exemplo, a promoção de saúde, bem-estar e educação (Contena et al., 2015). Com isso, Contena et al. (2015) argumentam que a utilização das informações dos usuários é benéfica quando realizada de forma que não fere a privacidade, isto é, não tomam as informações sem um consentimento.

Ainda com relação à saúde, a Internet proporcionou o surgimento de grupos de apoio a partir das comunidades virtuais. Welbourne, Blanchard e Wadsworth (2013) explicam que essas comunidades são caracterizadas por grupos de pessoas que interagem por via das tecnologias de informação e comunicação, como as redes sociais online, e que desenvolvem sentimentos de identidade, pertencimento e ligação uns com os outros. Tais grupos possibilitam a construção de um senso de comunidade virtual a partir de comportamentos como, por exemplo, a troca de informações e experiências. Essa troca acontece de maneira mais facilitada quando comparado com os grupos de apoio face a face, uma vez que a Internet proporciona a capacidade de superar restrições geográficas e temporais. Assim, os indivíduos portadores de problemas de saúde encontram nesses grupos dois tipos de apoio, o informativo e o emocional. $\mathrm{O}$ apoio informativo envolve o fornecimento de fatos, fontes ou referências relacionadas à saúde (como 
livros ou sites), conselhos e sugestões de cursos de ação ou tratamento. Já o apoio emocional inclui expressões de empatia e incentivo relacionados a preocupações com a saúde (Taiminen, 2016; Welbourne, Blanchard, \& Wadsworth, 2013).

Mano (2014) também realizou uma pesquisa sobre os comportamentos pró-sociais, em específico as contribuições monetárias, caracterizadas pelo comportamento de doar dinheiro para organizações que realizam ações sociais. Entende-se por ações sociais os comportamentos que prestam auxílio para pessoas que sofrem de necessidades básicas como moradia, alimentação, saúde, entre outros. A autora argumenta que a doação monetária é uma expressão ética de como utilizar a Internet, e até mesmo consumir nesse ambiente, de forma a prestar suporte para as causas sociais.

Mesch (2012) explica que a estrutura da Internet incentiva os interagentes a se engajar em trocas mais estreitas em ambientes online do que em ambientes face a face. A comunicação mediada por computador (CMC) é tipicamente caracterizada por sinais visuais, auditivos e de contexto reduzidos, como sinais de status social. A Internet também permite que o usuário tenha maior controle sobre a comunicação, o que proporciona o tempo de rever e editar suas mensagens e considerar respostas. Com a comunicação verbal reduzida e uma maior controlabilidade, pode acontecer a redução das inibições, o que favorece a interação das pessoas no ambiente online. Assim, esse processo pode acarretar em um rápido desenvolvimento da confiança online que, por sua vez, pode levar ao aumento da auto-revelação online (Mesch, 2012).

Os comportamentos pró-sociais destacados até então são compatíveis com a educação da sensibilidade, pois demonstram que a Internet abriu o campo da interação social, expandindo a esfera da comunicação outrora restrita ao face a face para o espaço virtual. As mídias sociais aumentaram a conectividade individual com amigos, parentes, colegas e pessoas de interesses semelhantes, introduzindo uma nova maneira de apresentar ideias e se conectar com outras pessoas para compartilhar interesses. Eles desempenharam um papel importante na facilitação de muitas atividades e precipitaram o fluxo de informações entre os beneficiários online e os provedores de serviços sem fins lucrativos, expondo indivíduos a causas sociais (Contena et al., 2015; Mano, 2014). Tais fatores têm relação direta com a participação social de forma não individualista, pautada na ética e alteridade, o que condiz com as estratégias apresentadas por Abib (2007). Deste modo, os comportamentos relacionados à auto-revelação online podem ser compatíveis com a educação da sensibilidade, pois os benefícios hedônicos das trocas sociais mediadas por computadores são definidos por alguns autores como altruístas. $\mathrm{O}$ altruísmo explicado por Church, Thambusamy e Nemati (2017) é um prazer intrínseco que vem do comportamento de ajudar os outros, mesmo que não esperem nada em troca e as pessoas gozam de um comportamento altruísta em um ambiente social online.

Além disso, Vermeulen, Vandebosch e Heirman (2018) argumentam que quando compartilham suas emoções, as pessoas revivem eventos positivos ou negativos que causaram essas emoções. Assim, as redes sociais disponibilizam reforçadores positivos imediatos como, por exemplo, atenção, feedback, apoio, simpatia ou validação, os quais serão responsáveis por aumentar as chances de o comportamento de auto-revelação voltar a acontecer. Assim, o hedonismo existente nesses casos parece corresponder ao hedonismo que não se dá em detrimento do outro, isto é, o prazer individual não se realiza em prejuízo de outrem. Há também, nesses casos, o cuidado com os demais indivíduos pertencentes à relação cultural, demonstrando então a educação amorosa, conforme os termos de Abib (2007). Os comportamentos descritos parecem, então, ser compatíveis com a noção de educação do sentimento, uma vez que correspondem à educação amorosa, isto é, ao "sentimento de dever fazer o que é bom para si, para os 
outros, e para as culturas" (Abib, 2007, p. 71). Também são comportamentos que se relacionam com o autocontrole e com a formação do indivíduo criativo, uma vez que os reforçadores positivos imediatos são utilizados em prol da justiça e da ética, e também, demonstram a sensibilidade e compreensão dos indivíduos sobre os outros diferentes de si.

Outro comportamento importante apresentado por Hoffman, Jones e Yonug (2013) é o de engajamento político, que também pode ser descrito como pró-social. São comportamentos relacionados à atuação dos cidadãos em algum ato relacionado à política, o que também é considerado um ato de democracia. Alguns exemplos desses comportamentos citados por Hoffman et al. (2013) são: seguir ou fazer amizade com candidatos e representantes políticos nas redes sociais de comunicação, assinar petições online, doar dinheiro para campanhas, promover sua propaganda, discutir e conversar sobre política com outros cidadãos, participar de votações, entre outros.

Hoffman et al. (2013) argumentam que os comportamentos de engajamento político acontecem, originalmente, no ambiente off-line, e passaram a se dar também no âmbito online, e que a principal diferença entre os dois está na facilidade do acesso à informação permitido pela Internet. Explicam que os comportamentos de participação política dependem de algumas variáveis como o acesso à educação, renda financeira, pré-disposições psicológicas, partidarismos e mobilizações. Esses fatores originam-se em grande parte das instituições cívicas de organizações voluntárias, locais de trabalho e religiões. Com isso, Hoffman et al. (2013) descrevem que alguns estudiosos defendem que a Internet é um meio que aumenta, democraticamente, o engajamento político, já que permite que novas vozes sejam ouvidas, ou que as informações sejam divulgadas de maneira mais livre. Esse aumento é justificado pela facilidade de acesso proporcionado pela Internet, tanto pelas informações de trabalho quanto relativas à política.

De maneira geral, os comportamentos de engajamento político são responsáveis pela manutenção da cultura e da sociedade, pois, como explicado por Hoffman et al. (2013), comportamentos comunicativos como debates e discussões políticas são necessários para a manutenção da democracia seguindo os preceitos éticos necessários. Sendo assim, como apresentado por Abib (2007) na proposta da educação da sensibilidade, se fazem necessários comportamentos éticos, que promovam o diálogo entre os indivíduos a fim de que seus direitos sejam conquistados, respeitados e mantidos, com vistas a diminuir as desigualdades sociais. Promover atitudes políticas que respeitem as diferenças entre os indivíduos, e que prezam pelo bem-estar geral, é uma das principais estratégias da educação da sensibilidade, pois tem na sua base o hedonismo educado e a ética justa, que se relaciona com o sentimento de dever fazer o que é bom para toda a humanidade.

Com a discussão dos diferentes comportamentos pró-sociais descritos até então, pode-se observar que suas consequências podem ser consistentes com a educação da sensibilidade, uma vez que aparentam respeitar os seus princípios e cumprir com as estratégias. De uma perspectiva analítico-comportamental, trata-se de comportamentos que ocorrem devido a reforçadores positivos imediatos, mas que a longo prazo parecem não ameaçar as relações interpessoais, pois são baseados na empatia e alteridade. 


\section{Comportamentos desfavoráveis à educação da sensibilidade}

Comportamentos desfavoráveis são aqueles que não cumprem com os princípios e estratégias da educação da sensibilidade, ou que os ferem. Nos artigos analisados, são exemplificados e discutidos comportamentos variados e muitos apresentam as consequências negativas que são descritas por Abib (2007), isto é, nota-se o uso da punição, a produção de prazeres ao indivíduo em prejuízo do outro, e também o desequilíbrio entre prazeres e desprazeres, no qual se verifica a produção de prazeres imediatos mas que em longo prazo têm o potencial de tornarem desprazeres. Esses comportamentos podem ser enquadrados no que é descrito por Ferenczi et al. (2017) como comportamentos antissociais identificados na Internet, que são comportamentos considerados individualistas.

Um dos principais comportamentos identificados a partir destas interações mediadas é o comportamento de $c$ yber aggression. Trata-se de uma forma de comunicação, como conversas, publicações, entre outros comportamentos que têm a função de ofender alguém. Alguns autores vão definir tipos de cyber aggression como, por exemplo, o cyberbullying. Não há um consenso entre os estudiosos acerca de uma definição inequívoca do cyberbullying, mas as principais características mencionadas descrevem comportamentos que podem ser emitidos por uma ou mais pessoas, contra uma pessoa ou um grupo. Quanto à duração, para ser considerado um ato de cyberbullying é necessário que os ataques aconteçam por um período de tempo maior que um dia, caso contrário, se ocorrer em apenas um dia fica caracterizado como cyber aggression (France, Danesh \& Jirard, 2013; Näsi et al., 2014).

France, Danesh e Jirard (2013) argumentam que com a comunicação facilitada e devido as redes sociais online contarem com poucas regulamentações, as pessoas tedem a enviar conteúdos agressivos com mais frequência. Além disso, Näsi et al. (2014) também explicam sobre o comportamento de acessar sites violentos ou prejudiciais, como, por exemplo, sites relacionados a transtornos alimentares ou autoagressão, os quais possuem alta probabilidade de estar vinculado à autoimagem negativa dos usuários, possivelmente resultante de experiências negativas anteriores, ou uma perspectiva negativa da vida, ou o uso mais ativo ou arriscado dos usuários na Internet.

Workman (2011) descreve outro comportamento que se enquadra na definição de cyber agression, que é o c yber smearing. Esse último é definido, então, como o comportamento de fazer um pronunciamento na internet com a função de prejudicar um indivíduo ou uma corporação. $O$ autor associa ainda o cyber smearing ao que denomina de " rash impulsivity" (impulsividade eruptiva), que seria a capacidade que os indivíduos têm de se comportar no "calor do momento".

Um ponto principal é que os comportamentos de cyber smearing, cyberbullying e outros tipos de cyber agression são facilitados pela possibilidade de anonimato. Por isso, esses comportamentos estão relacionados com um fenômeno denominado "virtual self" que é definido por Workman (2011) como o comportamento de interagir com outras pessoas online utilizando identidades anônimas ou fictícias. Com a possibilidade do anonimato, ou de criar um perfil em que não é necessário que os usuários utilizem suas fotos pessoais, pode acontecer o processo de objetificação, que seria uma despersonalização do indivíduo que está do outro lado da relação mediada pelas redes sociais online. Esse processo afeta diretamente as relações que são estabelecidas, acarretando em falta de compreensão mútua e dificuldade de se identificar com os outros. Consequentemente, as pessoas tendem a categorizar e estereotipar mais facilmente os outros indivíduos (Workman, 2011).

São discutidos também outros comportamentos como a busca por atenção (attention-seeking) e o "trolar" ( bullying/trolling). Os comportamentos de busca por atenção são descritos como exibicionistas, e de caráter egoísta, de 
modo que o indivíduo emite comportamentos de auto-apresentação online, ou seja, publicações que relatem suas conquistas, ou até mesmo rotinas diárias cujo objetivo é apenas a exibição para os outros. Ferenczi et al. (2017) enquadram o comportamento de attention-seeking como um comportamento narcisista, em que o indivíduo busca um feedback social externo, ou seja, o indivíduo se exibe nas redes sociais com a função de receber os "likes" dos outros indivíduos, o que pode gerar uma dependência excessiva do outro, nos sentido de que uma experiência só se tornará válida ou relevante mediante aprovação alheia; ao mesmo tempo esse exibicionismo pode acentuar o caráter aversivo da situação vivida por alguma pessoa.

Similarmente, os comportamentos de "trolling", ou o "trolar" são descritos como um tipo de cyberbullying, e se caracterizam como comportamentos online que podem ser entendidos como a postagem de mensagens sutis ou ofensivas, bem como iniciar uma discussão ou um debate sem sentido. $O$ trolling evoca reações emocionais negativas em outras pessoas e não têm propósito aparente, mas no geral envolvem perturbar, caçoar ou enganar outras pessoas (Coles, West, Bartsch \& Dienlin, 2016; Ferenczi et al., 2017). De acordo com a pesquisa realizada por Ferenczi et al. (2017), esses comportamentos possuem a mesma operacionalização dos comportamentos exibicionistas e de busca por atenção, ou seja, o indivíduo "trola" alguém e gera como consequências reforçadores positivos imediatos generalizados, como, por exemplo, outras pessoas acham graça da publicação ou do comentário realizado, concordando ou "curtindo".

As consequências destes comportamentos são abordadas tanto no nível individual como também no social, pois algumas envolvem o grupo social no qual o sujeito está inserido, por exemplo, os amigos que a pessoa tem adicionada na sua rede social. Nesse caso, a busca por atenção pode ser prejudicial não só para o indivíduo como também para o círculo social que está envolvido. Segundo Meyer (2011) "um ambiente hostil pode levar as pessoas a se sentirem insignificantes, sem valor e podem sentir-se culpadas porque se consideram incapazes de promover ou adquirir o reforço desejado (e.g., o afeto do outro)" (p. 19).

Sendo assim, de acordo com o exposto, os comportamentos antissociais são desfavoráveis à educação da sensibilidade. Esses comportamentos ferem os princípios dessa educação, uma vez que são comportamentos que resultam em reforçadores positivos e/ou negativos aos seus emissores a curto prazo, pois, de acordo com France et al. (2013), ao atacar alguém os agressores sentem-se poderosos e superiores. Entretanto, a longo prazo esses comportamentos são prejudiciais para os emissores, já que geram dependência da aprovação constante do outro. Como explicitado anteriormente, o trolling produz consequências reforçadoras imediatas para o indivíduo em prejuízo dos outros. Do mesmo modo, o attention-seeking pode produzir reforçadores imediatos, mas em longo prazo pode gerar dependência do comportamento dos outros usuários.

Esses comportamentos se valem de punição, visto que apresentam eventos aversivos para o comportamento dos outros usuários. Além das consequências para os emissores desses comportamentos há também os sujeitos alvos desses comportamentos agressivos, como o cyberbullying e cyberagression, pois são comportamentos que produzem irritação ou eventual maximização de aspectos negativos da vida. Além disso, mesmo que os agressores tenham a impressão de que por ocorrer no ambiente virtual a agressão não fará nenhum mal efetivo, os autores citam que: "Alvos de agressão cibernética experimentaram ansiedade, depressão, tristeza, frustração, raiva, vergonha, medo, desânimo, sentimentos de isolamento, e pensamento suicida . . . e alguns se mataram" (France, et al., 2013, p. 2144). Deste modo, os comportamentos antissociais até então citados são comportamentos que utilizam dos reforçadores positivos imediatos que ameaçam os outros indivíduos e a própria cultura, bem como se valem da 
punição. Sendo assim, não cumprem com os princípios da educação da sensibilidade, e, por conseguinte, não podem ser entendidos como estratégias para promovê-la, já que são comportamentos definidos, pela sua função, como antiéticos e egoístas.

\section{CONSIDERAÇÕES FINAIS}

Diferentes repertórios comportamentais tornaram-se possíveis com o advento da cultura e as alterações que esta produziu no ambiente em que o ser humano está inserido. De acordo com Wang, Pereira e Andery (2016), as redes sociais online contribuíram para o desenvolvimento e a expansão de diferentes formas de relações sociais. Elas foram se tornando cada vez mais mediadas e complexas. Com os dados obtidos, pode-se inferir que o ambiente das redes sociais online apresenta comportamentos favoráveis e desfavoráveis à educação da sensibilidade.

Os comportamentos favoráveis à educação da sensibilidade são aqueles que se pautam nos princípios e nas estratégias da educação da sensibilidade. De modo geral, os comportamentos que se enquadram na definição de compatíveis, ou favoráveis, à educação da sensibilidade, são os pró-sociais. Como explicado anteriormente, são os comportamentos que geram como consequências o relacionamento com outros indivíduos por meio da Internet, pautados na alteridade e na ética, buscando prazeres que não oprimam os demais usuários. Por outro lado, também são emitidos comportamentos que não favorecem a educação da sensibilidade, pois são inconsistentes com os seus princípios e estratégias. São os casos de comportamentos antissociais, caracterizados como violentos, egoístas, que terão como consequências o prazer próprio em detrimento do prazer dos outros indivíduos. São comportamentos baseados no hedonismo não educado. Trata-se do hedonismo presente na natureza e que se dá de forma rápida e imediata, mas que a longo prazo se mostra prejudicial para a o indivíduo e para a cultura (Abib, 2007).

Além disso, os autores dos artigos apresentam opiniões diversificadas, o que constitui uma visão pluralista, isto é, as relações sociais online não são completamente boas, nem exclusivamente nocivas, como 0 são as relações sociais que se dão no mundo off-line. Mas, tal como sugere Mano (2014), os comportamentos online podem ser apenas extensões dos comportamentos já praticados no mundo off-line? Se isso for assim, indaga-se, então: é necessário que haja a aplicação da educação da sensibilidade que preceda o uso das redes sociais online?Deste modo, questiona-se a possibilidade das redes sociais online se tornarem uma estratégia para a educação da sensibilidade, sem que seus efeitos já não tenham se verificado previamente no repertório comportamental dos indivíduos.

Sendo assim, a estrutura das redes sociais online pode presumivelmente potencializar um repertório comportamental sensivel, desde que ele já exista, sendo necessário sondar se é possível desenvolvê-lo apenas e primeiramente no âmbito das relações online. Entretanto, a maneira como a Internet está organizada acaba dificultando o desenvolvimento de um equilíbrio entre as sensibilidades, uma vez que as relações são mediadas e as consequências dos comportamentos de prejudicar o outro são atrasadas. Com isso, a educação da sensibilidade pode se fazer presente nas redes sociais online, mas também pode ser inviabilizada devido a formas com a qual se dão as relações sociais online que não se verificam nas relações off-line face a face (possibilidade de anonimato, perfis falsos, "bloquear" o contato com pessoas de opiniões discordantes, etc.). Por fim, para trabalhos futuros, sugere-se investigar a relação entre os comportamentos online e off-line, a fim de compreender as suas possíveis influências recíprocas, de modo que um repertório comportamental sensível possa ser desenvolvido e promovido em diferentes 
formas de interação social.

\section{REFERÊNCIAS}

Abib, J. A. D. (2007). Comportamento e sensibilidade: Vida, prazer e ética. Santo André, SP: ESETec Editores Associados.

Bogo, A. C. (2017). Educação da sensibilidade: Contribuições ao planejamento cultural (Dissertação de Mestrado). Universidade Estadual de Londrina, Londrina, PR, Brasil.

Bogo, A. C., \& Melo, C. M. de. (2019). Contribuições do projeto de educação da sensibilidade de Abib ao planejamento cultural. Acta Comportamentalia, 27(3), 269-286.

Bryce, J., \& Fraser, J. (2014). The role of disclosure of personal information in the evaluation of risk and trust in young peoples' online interactions. Computers in Human Behavior,30,

299-306. doi:https://doi.org/10.1016/j.chb.2013.09.012.

Carvalho Neto, M. B. de, Alves, A. C. P., \& Baptista, M. Q. G. (2007). A consciência como um suposto antídoto para a violência. Revista Brasileira de Terapia Comportamental e Cognitiva, 9(1), $27-44$. doi:https://doi.org/10.31505/rbtcc.v9i1.144.

Church, E. M., Thambusamy, R., \& Nemati, H. (2017). Privacy and pleasure: A paradox of the hedonic use of computer mediated social networks. Computers in Human Behavior,77, 121-131. doi:https://doi.org/10.1016/j.chb.2017.08.040.

Contena, B., Loscalzo, Y., \& Taddei, S. (2015). Surfing on social network sites: A comprehensive instrument to evaluate online self-disclosure and related attitudes. Computers in Human Behavior, 49, 30-37. doi: https://doi.org/10.1016/j.chb.2015.02.042.

Coles, B. A., West, M. Bartsch, M., \& Dienlin, T. (2016). Trolling the trolls: Online forum users constructions of the nature and properties of trolling. Computers in Human Behavior,60, 233-244. doi:https://doi.org/10.1016/j.chb.2016.02.070.

Ferenczi, N., Marshall, T. C., \& Bejanyan, K. (2017). Are sex differences in antisocial and prosocial Facebook use explained by narcissism and relational self-construal? Computers in Human Behavior, 77, 25-31. doi:https://doi.org/10.1016/j.chb.2017.08.033.

France, K., Danesh A. B., \& Jirardet, S. al. (2013). Informing aggression-prevention efforts by comparing perpetrators of brief vs. extended cyber aggression. Computers in Human Behavior, 29, 2143-2149. doi:https://doi.org/10.1016/j.chb.2013.05.011

Hoffman, L. H., Jones, P. E., \& Yonug, D. G. (2013). Does my comment count? Perceptions of political participation in an online environment. Computers in Human Behavior, 29, 2248-2256. doi:https://doi.org/10.1016/j.chb.2013.05.010

Kimbrough, A. M., Guadagn, R. E., Nicole L., Muscanell, N. L., \& Dill, J. (2013). Gender differences in mediated communication: Women connect more than do men. Computers in Human Behavior, 29, 896-900. doi:https://doi.org/10.1016/j.chb.2012.12.005. 
Lopes, C. E.; Laurenti, C. (2015). Reflexões comportamentalistas sobre a maldade contemporânea. In C. Laurenti \& C. E. Lopes (Orgs.). Cultura, democracia e ética: Reflexões comportamentalistas. Maringá: EDUEM, 1.

Mano, R. S. (2014). Social media, social causes, giving behavior and money contributions. Computers in Human Behavior, 31, 287-293. doi:https://doi.org/10.1016/j.chb.2013.10.044.

Mesch, G. S. (2012). Is online trust and trust in social institutions associated with online disclosure of identifiable information online? Computers in Human Behavior, 28, 1471-1477. doi:https://doi.org/10.1016/j.chb.2012.03.010.

Meyer, D. de S. T. (2011). A autoestima na perspectiva da análise do comportamento. (Monografia). Instituto Brasiliênse de Análise do Comportamento, Brasília, DF, Brasil.

Näsi, M., Räsänen, P., Oksanen, A., Hawdon, J., Keipi, T., \& Holkeri, E. (2014). Association between online harassment and exposure to harmful online content: A cross-national comparison between the United States and Finland. Computers in Human Behavior,41, 137-145. doi:https://doi.org/10.1016/j.chb.2014.09.019.

Soares, P.; Carvalho Neto, M. B. de. (2016). Agressão e análise do comportamento: a história do modelo de "pain-aggression". Revista Brasileira de Análise do Comportamento, 12(1),

65-74. doi:http://dx.doi.org/10.18542/rebac.v12i1.4024.

Skinner. B. F. (2003). Ciência e comportamento humano. São Paulo: Martins Fontes, 11. (Trabalho original publicado em 1953).

Taiminen, H. (2016). How do online communities matter? Comparison between active and non-active participants in an online behavioral weight loss program. Computers in Human Behavior,63,

787-795. doi:https://doi.org/10.1016/j.chb.2016.06.002.

Vermeulen, A., Vandebosch, H., \& Heirman, W. (2018). \#Smiling, \#venting, or both? Adolescents' social sharing of emotions on social media. Computers in Human Behavior, 84, 211-219. doi:https://doi.org/10.1016/j.chb.2018.02.022

Wang, M. de L., Pereira, M. E. M., \& Andery, M. A. (2016). Mídia, comportamento e cultura. Perspectivas em Análise do Comportamento, 7(2), 147-164. doi:http://dx.doi.org/10.18761/pac.2015.024.

Welbourne, J. L.; Blanchard, A. L.; Wadsworth, M. B. (2013). Motivations in virtual health communities and their relationship to community, connectedness and stress. Computers in Human Behavior, 29, 129-139. doi:https://doi.org/10.1016/j.chb.2012.07.024.

Workman, M. (2011). Rash impulsivity, vengefulness, virtual-self and amplification of ethical relativism on cyber-smearing against corporations. Computers in Human Behavior, 28 , 217-225. doi:https://doi.org/10.1016/j.chb.2011.09.003. 